\title{
Will the Global Financial Crisis Change the Development Paradigm?
}

\author{
Neil McCulloch and Andy Sumner
}

\begin{abstract}
The depth and breadth of the current crisis has led many to suggest it will fundamentally change development thinking and practice. We review four ways in which the crisis may affect the 'development paradigm': changes to global economic governance; new thinking on development policy; opportunities to institutionalise social protection; the implementation of a Green New Deal. The global financial crisis may change the development paradigm through its impact on the attitudes of developing country policymakers towards the prevailing policy prescriptions, rather than through major structural changes in global economic governance. Although the geopolitical and attitudinal changes will be significant, it is likely that the development paradigm after the crisis will be similar to that before. A greater tendency for developing countries to explore new development models and to rely on their own analysis and knowledge to fashion solutions to their problems, could be a positive outcome of this crisis.
\end{abstract}

\section{Introduction}

This financial crisis is no ordinary crisis. Its origin, depth and severity and the speed with which it has spread around the globe are likely to lead to profound changes in the way that policymakers throughout the world think about development policy. The articles in this IDS Bulletin have focused on what we know about the impact of the crisis on developing countries. In this conclusion, we take the opportunity to speculate more broadly about the potential effect of the crisis on the face of development as we know it. We start by asking, What is new and different about this crisis that may make this crisis qualitatively different from previous downturns and recessions? We then explore the major institutional and policy shifts that may result from this crisis, as well as the likelihood of major changes to policies on social protection and low-carbon growth. We conclude with our own assessment of the likely outcome and some pointers to the appropriate focus for future research.

\section{What is different about this crisis?}

This is not the first recession which the world has seen, nor will it be the last. All countries' economies are subject to business cycles - the US economy, for example, has experienced 32 recessions since 1854; 11 since World War II. ${ }^{1}$ We suggest three factors that make this recession qualitatively different in its impact on developing countries from previous downturns.

First, this crisis started in the rich world. Almost all of the major crises which have affected developing countries in the last 20 years have originated in developing countries themselves (e.g. Latin American debt crisis of the 1980s; Mexico 1994; East Asia 1998; Russia 1998; Brazil 1999; Argentina 2000). Their impact has therefore been severe, but localised to the country affected or a group of closely linked economies. By contrast, this crisis, because it originated in the world's largest economy, will have a much broader and deeper impact.

Second, precisely because this is first and foremost a financial crisis, it has spread rapidly around the entire globe. For the first time since World War II, almost all of the major world economies are contracting simultaneously. This makes its impact on small developing countries much more severe, since there are no alternative markets to which their exports can easily be directed. 
Third, and crucially, the size of the shock is huge. Industrial production has plummeted and several countries are experiencing double digit reductions in their GDP. The sheer size of the recessions experienced and their rapid transmission around the world ensure that the crash of 2008 will, without question, be the largest financial and economic crisis since 1929.

\section{A new development paradigm?}

A shock of the magnitude of the current crisis will have effects which long outlast the immediate economic impact. We sketch out some of the changes which may happen and their wider implications for development.

\subsection{A new era for global economic governance?}

The crisis has demonstrated the extraordinarily high level of interdependence of economies around the globe. This has placed in sharp relief the inadequacy of today's international institutions to identify and respond to the crisis. The failings are manifold.

First, as has been discussed extensively elsewhere (Brunnermeier et al. 2009), there is a lack of international financial regulation and institutions capable of monitoring and enforcing such regulations. The weaknesses of relying on national financial regulators to deal with global financial markets have been only too apparent in the current crisis. The crisis has already led to measures to strengthen cross-country collaboration between financial regulators; much tighter restrictions on tax havens, and the inclusion of hedge funds and other systemically significant entities into the remit of supervisors. It will almost certainly result in the abandonment of the Basle II reliance on individual firm risk models for assessing risk, and the implementation of broader forms of macro-prudential supervision.

Second, the urgent need to broaden representation in the institutions of global economic governance is apparent. The crisis has resulted in a high profile process of institutional outreach to emerging powers through the G20 forum rather than the traditional G7/8 forum. More broadly, the crisis has brought open recognition that we live in a multipolar rather than a unipolar world. This may lead to a greater emphasis on multilateralism, on new alliances and changes in the balance of global power, particularly through a greater role for major emerging economies such as Brazil, Russia, India and, particularly, China, in the governance of global institutions. However, although this broadening of representation in global fora includes 'systemically significant' developing countries, it still excludes the voices of almost all African countries and the large majority of developing nations. At present, there seems little prospect of this changing, which may damage the perceived legitimacy of those institutions in the rest of the developing world.

Third, current global economic institutions lack the funds and the ways of operating which are needed to respond to a crisis of this kind. The G20 summit in April 2009 saw significant increases in the resources of the IMF and the World Bank, as well as steps to improve the flexibility and speed with which resources can be used (G20 2009). Whether these increases in resources and new instruments will be sufficient to meet the needs of their many clients remains to be seen. Past performance does not give much cause for optimism (Gottschalk and Bolton, this IDS Bulletin).

But the reforms needed in these institutions go far beyond additional resources. ${ }^{2}$ The reality is that the IMF in particular is not seen by many developing countries as their institution working on their behalf, but rather as a Western institution, which imposes unwelcome policy prescriptions upon countries facing economic crisis. It is noteworthy that, when Pakistan needed a loan, it turned (unsuccessfully) to China before the IMF. Most countries still do all they can to avoid the stigma of borrowing from the IMF. To be effective as a form of international insurance against macroeconomic shocks, the IMF must shift from a 'Poor Law' model to an 'insurance' model. In the former, a country must exhaust all other options and then suffer the shame and stigma of receiving IMF support. As a result, responsible governments in need of support do everything they can to avoid it, while irresponsible governments promise adherence to conditions in order to obtain support that they should not receive. An insurance model, by contrast, would provide support by right when a pre-agreed set of circumstances arise, but not when the conditions of the insurance are violated.

Two key changes need to be made to achieve such a change. First, there needs to be a dramatic 
restructuring of the voting structure of the IMF. Because the USA continues to hold 17 per cent of the votes, it has an effective veto on all key votes (since the quorum is 85 per cent). The current proposals for voting reform make minor adjustments, but fail to even begin to create a voting structure which would give developing countries serious ownership of the institution (e.g. even after the proposed reforms Belgium's voting share will be larger than Brazil's) (The Economist 2009). Second, it should be possible for the IMF and the World Bank to be led by someone from the developing world. The G20 summit saw the reiteration of the desire to see the heads of both institutions selected on merit, but the timetable set for agreeing such reforms is lamentably slow.

Aside from the reform of the Bretton Woods institutions, the Commission of Experts of the President of the General Assembly of the UN has called for the creation of an independent panel of experts to advise the General Assembly and the UN Economic and Social Council (ECOSOG, modelled along the lines of the Intergovernmental Panel on Climate Change), as well as a Global Economic Coordination Council of similar standing to the current Security Council (UN 2009). Whether these recommendations will be taken up is unclear at present. However, the difficulty in achieving international agreement on important structural changes in the systems of global economic governance is illustrated by the postponement of the UN Conference on the World Financial and Economic Crisis and its Impact on Development due to strong disagreements about the text of the draft agreement.

In summary, the crisis has opened the world's eyes to the systemic significance of large developing countries and the interdependence of all. It is likely to boost the representation and power of a handful of large developing nations. At the same time, current proposals suggest that there will not be major changes to the ways in which the World Bank and the IMF operate. Moreover, despite a symbolic widening to the G20, some of the most important strategic issues appear to be narrowing to a G2 consisting of the USA and China.

\subsection{A new approach to development policy?}

The reductions in poverty that have happened over the last 20 years have largely been fuelled by export-led growth. Yet in a global recession, this past engine is an unlikely route for recovery. It is also clear that more open countries have been the most vulnerable to economic downturn in this crisis (see Robinson and Willenbockel, this IDS Bulletin). As a result, analysts and policymakers across the world are questioning the effectiveness of global integration as a pathway towards prosperity. The next decade could see a repeat of the de-globalisation experienced in the early twentieth century, including restrictions on the international movement of capital and greater protectionism (Williamson and O'Rourke 2001). Such a change could be disastrous for global growth and poverty reduction. For this reason, G20 leaders have been at pains to emphasise the importance of keeping borders open. But in practice, protectionist measures have been increasing and there is little sign of an early conclusion of the Doha round of trade talks.

In fact, the reappraisal of the role of international integration for development is part of an intellectual shift that was already happening prior to the crisis. The importance of the relationship between openness and growth has been strongly contested in the literature (Rodrik et al. 2004), although there is no convincing evidence that being closed is good for growth either (Rodriguez and Rodrik 1999). Rodrik in particular has argued strongly that developing countries need to be allowed the policy space to re-think their interactions with global markets (Rodrik 2008).

More broadly, IDS's work on crisis narratives suggests that developing country policymakers may have less respect for, and less interest in, policy prescriptions from the West (Schmidt et al., this IDS Bulletin). In particular, many countries are looking East for new models of development. Cook and $\mathrm{Gu}$, in this IDS Bulletin show the need for greater understanding of China's evolving role in development, as many countries begin to see China's approach as an alternative to the Washington Consensus model of development. The influence of China's state-driven approach, as well as the huge state interventions undertaken by Western governments during the last year, are likely to legitimise a greater role for the state in the economy in the minds of many developing country policymakers. Similarly, the trend towards tighter financial regulation may well be mirrored in a general tendency for increased government regulation of the economy. 
The final outcome of such a shift in the intellectual climate will not be known for some years. Whether these shifts are positive or negative, depends on how policy responses tackle today's problems and learn from the lessons of the past. A greater tendency for developing countries to explore new development models and to rely on their own analysis and knowledge to fashion solutions to the problems they face, could be a positive outcome of the crisis. Similarly, it may be desirable for developing countries to be given greater flexibility within international agreements to implement policies that they feel are appropriate for their situation.

The principle concern is that policies which may have been effective, will be discredited along with those that have not worked. For example, international integration has been strongly beneficial for many countries - an ideological shift towards 'internally' generated growth may threaten these gains. Similarly private sector competition has often improved efficiency in formerly state-owned sectors - a return to high levels of state ownership in industry may not boost growth. The best outcome will neither be a return to the Washington Consensus, nor the abandonment of it, but rather a new pragmatic consensus, in which policy is based on the analysis of the best available evidence for each country's unique context.

\subsection{A new opportunity to protect the poor}

Moments of crisis also present windows of opportunity. Just as the depression in 1930s USA gave birth to the New Deal, there has been much talk of a Global New Deal. One way to make this a reality would be to take this opportunity to institutionalise social protection in sub-Saharan Africa.

The last ten years have seen extensive development of social protection in Africa. The largest programmes are in Ethiopia and South Africa, but pilots, some large, are emerging in Kenya, Zambia and Ghana. Moreover, there is a lot more evidence now about what sorts of programmes are most effective and how to target and improve the livelihoods of different groups.

However, it remains the case that few of these schemes are long-term or at scale. The vast majority of the most vulnerable people in the world's most vulnerable continent still lack effective, systematic social protection (Ellis et al. 2009).

There is a danger that the crisis may not change the level of social protection in practice if we do not make the rhetoric reality but if voice is improved - people are aware of their entitlements and can claim them - we could move forward. Key to changing this is the generation of greater demand for and ownership of social protection programmes by both African governments and their citizens. For example, Brown et al. (2009) show that a key reason for the success of the large-scale social protection programme in Ethiopia is local ownership. The Ethiopian government was keen to change its international image as a famine-ridden, hopeless country. Further, providing social protection was much cheaper than emergency aid, while the 'productive' aspect of the safety net helped to justify the resources devoted to the programme because the poor worked for their money. Social protection, therefore, proved to be timely, predictable and adequate, and, unlike emergency aid, is available before the poor lose their assets due to a shock.

However, there are many impediments to broader provision of social protection. These include the radical shift that it can require in ways of doing things, as well as limited capacity for implementation in some countries. Thus, despite more commitment and additional resources, most social protection in sub-Saharan Africa is still donor-driven. Much more needs to be known about the key political processes of policy formation and implementation and how to build effective demand for greater social protection. It will be important to learn lessons from those countries in both Asia and Latin America, where local ownership of social protection by governments is real.

To what extent will the crisis help to create momentum for much greater social protection in Africa? The evidence to date is mixed. On the one hand, there has been much discussion, globally, of the need for greater social protection. The President of the World Bank called for 0.7 per cent of developed country stimulus packages to be devoted to supporting developing countries, with social protection featuring strongly in this support (Zoellick 2009). Similarly, the UN Commission of Experts recommended that 1 per cent of such 
packages be devoted to this purpose. The crisis has also led to the UN proposal for a 'social protection floor' and to the World Bank's Vulnerability Financing Facility (VFF) including the Global Food Crisis Response Program and the new Rapid Social Response Program, which will help to create new global partnerships to share experience, evidence and ideas on how to effectively extend social protection (see also Davies and McGregor, this IDS Bulletin).

But it is not clear how much this increase in rhetoric will translate into concrete action at the country level. Even the additional resources are not what they seem at first glance. The VFF is an umbrella for a set of World Bank initiatives, several of which are not new, and not all of the new donor resources announced for social protection have proved to be new funds. More fundamentally, if the advocates for greater spending on social protection at the country level consist only of donors, then this could be selfdefeating as the lack of local ownership by national governments will likely mean programmes which are less sustainable after the crisis. There is also a tension between putting in place emergency response measures, and introducing or broadening longer-term social protection programmes to address the structural vulnerabilities faced by the poor in each country. It is important that these are seen as complements rather than substitutes in responding to the crisis.

Perhaps most difficult of all is attempting to broaden social protection within an extremely constrained fiscal environment. Many African countries, far from being able to provide a stimulus, are likely to be looking for expenditure cuts to maintain macroeconomic stability in an environment of declining revenues. Expanding social protection therefore entails even larger cuts in other forms of expenditure. There is therefore an important link between the potential of the crisis for expanding social protection and the need for countries to be provided with flexible forms of official financing to cushion the budgetary impact of the crisis (Gottschalk and Bolton, this IDS Bulletin). In short, the crisis may increase the leverage of advocates of social protection in developing countries, but in many countries, their success will depend on whether donors are able to support sufficient fiscal space for the budget reallocations involved.

\subsection{A new commitment to a low-carbon future}

The large coordinated fiscal stimulus being undertaken by rich countries in response to the crisis presents a major opportunity to achieve a step-change to a lower carbon growth path. The potential damage that global warming may cause is immense. The costs of significantly slowing down the process are small in comparison - and similar to the size of the fiscal stimulus being undertaken to address the crisis. There is therefore a strategic opportunity to use a part of the stimulus to promote a shift to lower carbon technologies. To be effective, this will require the participation of major developing countries. This will depend on finding accountable forms of international environmental governance, which strike the right balance between the responsibility of all to reduce the harm to future generations and the right of all to development.

However, one of the difficulties in using the opportunity of the crisis to build commitment for low-carbon development, is that there are several different interpretations of what low carbon development means. Table 1 gives four contrasting interpretations, resulting from where policymakers place themselves on two different dimensions of response: their approach to growth; and their focus on production or consumption related policy measures. The first two types of low carbon development (Green economy and Green lifestyles) assume that economic growth is compatible with significant reductions in carbon emissions - the latter two (Equilibrium economy and Coexistence with nature) assume it is not. The Green economy and Equilibrium economy approaches both put the emphasis on reducing the production of carbon through technological changes, while the Green lifestyles and Coexistence with nature approaches focus on reducing demand through lifestyle and behavioural changes.

The options presented in Table 1, of course, are not all mutually exclusive. For example, most country policymakers will favour a mix of production- and consumption-side approaches to low carbon development. However, the debate about the appropriate mix of policy measures in each country is still ongoing. As a result, there is little consensus within the governments of major emitters about what a green stimulus should be spent on. 


\title{
Green economy
}

This approach focuses on the production-side of an economy and on how goods and services can be produced with lower emissions. It aims at decoupling economic growth from carbon emissions (e.g. halving emissions, but doubling GDP).

\section{Green lifestyles}

This approach focuses on the consumption-side of a growing economy and on the consumer's ability to reduce emissions by consuming climate-friendly products. It implies lifestyle changes and behavioural changes and also leads to a decoupling of carbon emissions (e.g. halving emissions, but doubling GDP).

\section{Equilibrium economy}

\section{Focus mainly on mitigation, although adaptation also plays a role}

Focus equally on mitigation and adaptation

\section{Technological change,} sectoral change

\author{
Behavioural changes, \\ sectoral change, \\ technological change
}

This approach focuses on the production-side of an economy and aims at development rather than growth. No decoupling is necessary, as growth is neutral (e.g. halving emissions, but keeping GDP stable).

\author{
Focus mainly on \\ mitigation, although \\ adaptation also \\ plays a role
}

\section{Coexistence with nature}

This approach focuses on the consumption-side of an economy and aims at development rather than growth. No decoupling is necessary as growth is neutral (e.g. halving emissions, but keeping GDP stable).

\section{Focus equally on mitigation and adaptation}

Technological change, sectoral change

Source Urban and Sumner (2009).

At the same time, governments providing a fiscal stimulus have been under strong political pressure to implement such measures as quickly as possible, and to protect or create as many jobs as possible in the process. This has given an inevitable bias towards projects which are in a position to spend money quickly and likely to employ large numbers of people. Both of these factors can mitigate against long-term investment in 'green' infrastructure. It remains to be seen, therefore, whether the fiscal stimulae being undertaken will live up to their potential as a means of creating a step-change in lowcarbon development.

\section{Conclusions}

We conclude with notes of both optimism and pessimism.

On the optimistic side, it seems likely that this crisis will result in much greater activism by developing countries in the design and implementation of their own development policies. The Washington Consensus was already under siege before the crisis - it is now dead - at least in the sense that Western policy prescriptions are perceived by many developing country policymakers as having been completely discredited by this crisis. The hope is that we will see the emergence of development policies which are much more context- and country-sensitive as a result.

There also appears to be a significant shift towards greater engagement of development country policymakers in the discussion and formulation of policies for international economic cooperation. However, our optimism is tempered here. The geopolitical shift that we observe results in the inclusion of systemically significant developing countries - but the vast majority are still likely to be left out. Moreover, the shifts in the governance of the International Financial Institutions (IFIs) seem, although large by the standards of a year ago, to do very little to alter the status quo of power in those institutions.

Unfortunately, there is also much to be pessimistic about. For all the rhetoric about the need to protect the vulnerable, the opportunity 
to institutionalise broader and effective social protection, particularly in Africa, seems likely to be missed. Similarly, the Green New Deal may amount to much less than hoped, in part because countries are still attempting to negotiate the size and nature of the commitments that they intend to make in Copenhagen in December.

There is also significant concern about the impact of the crisis on the long-term development prospects of some of the world's poorest countries. In particular, the extensive debt relief offered to many of the poorest countries in 2005 and 2006 may simply have given space for the build up of more debt, as governments struggle to reign in expenditures. The financial crisis of 2008/09 may beget a debt crisis a few years down the line in sovereign debt (Ladd 2009).

At the same time, it is perhaps a source of relief that the poorest countries are, in general, not those hardest hit by the current crisis. Rather the economies that are suffering most in the short-term, are the export-oriented and increasingly high-tech economies that have gained most so far from globalisation (notably those in Asia), as well as those heavily dependent on the export of oil. But this is hardly good news. The growth reversals of some of these countries have been catastrophic, shaking faith in the export oriented development model that has

\section{Notes}

1 See: www.nber.org/cycles.html

2 There is substantial literature on reform of the World Bank and the IMF - see, e.g. the Global Economic Governance programme at the University of Oxford

\section{References}

Brown, T.; Gibson, S. and Ashley, S. (2009) Building Consensus for Social Protection: Insights from Ethiopia's Productive Safety Net Programme, London: The IDL Group, DFID

Brunnermeier, M.; Crockett, A.; Goodhart, C.; Persaud, A.D. and Shin, H. (2009) 'The Fundamental Principles of Financial Regulation', Geneva Reports on the World Economy 11, preliminary conference draft, prepared for presentation at a conference in Geneva, 24 January, Geneva: International Center for Monetary and Banking Studies (ICMB) been pursued. There has been much talk of a shift to 'internally' generated growth. This may well make sense for China or India with huge domestic markets, but is completely impossible for the vast majority of small developing economies.

The global financial crisis may change the development paradigm - but it is most likely to do so through its impact on the attitudes of developing country policymakers towards the prevailing policy prescriptions, rather than through major structural changes in global economic governance. Unfortunately, we will not know the significance of the changes that do occur, for some time. This has important implications for the research agenda going forward. To date, most work on the crisis (including this IDS Bulletin) has focused on assessing the likely impact, and prescribing suitable immediate policy responses. The next major research agenda should be to describe what actually happened and to understand why and to prescribe more medium- and longer-term policy responses. This may not help respond to the current crisis, but it could point towards policies that would increase the resilience of developing countries to the future crises that will occur. In the meantime, the optimists believe that we will return to business-as-usual very soon - and the pessimists believe that they are right.

(www.globaleconomicgovernance.org); the Centre for Global Development in Washington DC (www.cgdev.org); the Overseas Development Institute in the UK (www.odi.org.uk) and the selection of articles on VoxEU (www.voxeu.org).

The Economist (2009) 'Leaders: Banking on the Fund: The G20 and the IMF', The Economist 391.8626, 11 April: 12

Ellis, F.; Devereux, S. and White, P. (2009) Social Protection in Africa, Cheltenham: Edward Elgar

G20 Communiqué (2009) The Complete Statement of Agreement Announced by World Leaders After Today's Summit in London, 2 April, www.timesonline.co.uk/tol/news/politics/G20/a rticle6023679.ece (accessed 27 May 2009)

Ladd, P. (2009) The 2015 Debt Crisis, Brazil: The International Policy Centre for Inclusive Growth, http://econpapers.repec.org/ paper/ipcopager/84.htm (accessed 1 June 2009) 
Rodriguez, F. and Rodrik, D. (1999) Trade Policy and Economic Growth: A Skeptic's Guide to Cross National Evidence, NBER Working Paper 7081, Cambridge MA: NBER Program(s) III, National Bureau of Economic Research Rodrik, D. (2008) 'Industrial Policy for the Twenty-First Century', in D. Rodrik (ed.), One Economics, Many Recipes: Globalization, Institutions and Economic Growth, Princeton NJ: Princeton University Press; 99-152

Rodrik, D.; Subramanian, A. and Trebbi, F. (2004) 'Institutions Rule: The Primacy of Institutions Over Geography and Integration in Economic Development', Journal of Economic Growth 9.2: 131-65

United Nations (2009) Recommendations by the Commission of Experts of the President of the General
Assembly on Reforms of the International Monetary and Financial System, www.un.org/ga/president/ 63/letters/recommendationExperts200309.pdf (accessed 1 June 2009)

Urban, F. and Sumner, A. (2009), After 2015:

Promoting Pro-Poor Low Carbon Development, In Focus 9.4, Brighton: IDS

Williamson, J.G. and O'Rourke, K. (2001) Globalization and History: The Evolution of a Nineteenth-Century Atlantic Economy, London: MIT Press

Zoellick, R.B. (2009) 'A Stimulus Package for the World', New York Times, 22 January, www.nytimes.com/2009/01/23/opinion/ 23zoellick.html?_r=2 (accessed 1 June 2009) 